\title{
Nanoemulsion of eucalyptus oil and its larvicidal activity against Culex quinquefasciatus
}

\author{
S. Sugumar ${ }^{1}$, S.K. Clarke ${ }^{1}$, M.J. Nirmala ${ }^{1}$, B.K. Tyagi $^{2}$, \\ A. Mukherjee ${ }^{1}$ and N. Chandrasekaran ${ }^{1 *}$ \\ ${ }^{1}$ Centre for Nanobiotechnology, VIT University, Vellore, India: ${ }^{2}$ Centre for \\ Research in Medical Entomology, Madurai, India
}

\begin{abstract}
Filariasis is a mosquito-borne disease that causes lymphedema and the main vector is Culex quinquefasciatus. A simple measure was taken to eradicate the vector using nanoemulsion. Eucalyptus oil nanoemulsion was formulated in various ratios comprising of eucalyptus oil, tween 80 and water by ultrasonication. The stability of nanoemulsion was observed over a period of time and 1:2 ratios of eucalyptus oil $(6 \%)$ and surfactant $(12 \%)$ was found to be stable. The formulated eucalyptus oil nanoemulsion was characterized by transmission electron microscopy and dynamic light scattering. The nanoemulsion droplets were found to have a Z-average diameter of $9.4 \mathrm{~nm}$ and were spherical in shape. The larvicidal activity of eucalyptus oil nanoemulsion and bulk emulsion was tested and compared. Our nanoemulsion showed higher activity when compared to bulk emulsion. The histopathology of larvae-treated and untreated nanoemulsion was analyzed. Furthermore, biochemical assays were carried out to examine the effect of nanoemulsion on biochemical characteristics of larvae. The treated larval homogenate showed decrease in total protein content and a significant reduction in the levels of acetylcholinesterase. The levels of acid and alkaline phosphatase also showed reduction as compared to control larval homogenate.
\end{abstract}

Keywords: eucalyptus oil, filariasis, histopathology, larvicidal activity, nanoemulsion, ultrasonication

(Accepted 29 November 2013; First published online 9 January 2014)

\section{Introduction}

Filariasis is a disease that is caused by nematodes. These nematodes are transmitted to humans via mosquitoes during a blood meal (CDC, Global Health, 2010). Mosquitoes are a serious threat to public health as they act as vectors that

*Author for correspondence

Phone: 914162202624

Fax: 914162243092

E-mail: nchandrasekaran@vit.ac.in help in transmission of diseases that can be morbid and fatal (Becker et al., 2003). Owing to lack of proper medication and vaccines for treating mosquito-borne diseases, an alternative and effective approach used to control the vector population at the larvicidal stage is necessary, because, during this stage the mosquitoes are immobile. This can be done by the application of insecticides to larval habitats (Tennyson et al., 2012).

The resistance to synthetic pesticides and harmful effects of their accumulation in the environment has created the need for natural and non-persistent insecticides. The essential oils extracted from plants are suitable as they are economically 
reasonable and have high activity in certain cases (Silva et al., 2008) and are also bio-degradable (Sukumar et al., 1991).

Eucalyptus is a diverse genus of flowering trees and shrubs in the Myrtle family, Myrtaceae. The oil extracted from eucalyptus leaves possesses allelopathic property and prevents insects from attacking it, thereby, acting as a natural pesticide (Brooker \& Kleinig, 1990; Batish et al., 2008). In assays, such as, fumigation activity (Papachristos \& Stamopoulos, 2004) and repellency (Trigg, 1996), the efficiency of eucalyptus oil has been demonstrated (Kumar et al., 2012).

Downsizing of natural oils to form nanoemulsions could be effective as larvicidal agents (Anjali et al., 2012). Nanoemulsions are emulsions whose droplet size is uniform and extremely small with the size ranging from 20 to $200 \mathrm{~nm}$. Nanoemulsions are metastable and their stability is determined by the method of preparation (Wang et al., 2007). Nanoemulsions can be formulated by two kinds of methods such as high-energy and low-energy emulsification methods. High-energy emulsification method comprises high-pressure homogenization and ultrasonication (Yilmaz \& Borchert, 2005; Takegami et al., 2008; Klang et al., 2012). Ultrasonication is most widely used method owing to its ease of use and it is an economical method. The low-energy emulsification technique comprises methods that exploit the chemical properties of a system to convert a microemulsion into a nanoemulsion (Bouchemal et al., 2004; Tadros et al., 2004; Anton et al., 2007; Sole et al., 2010). The use of nanopesticides would be a contemporary measure for the control of pests and reducing the toxic effect of synthetic bulk pesticides on the environment (Suresh Kumar et al., 2013). Recently, controlling for vectorborne diseases using neem oil nanoemulsion will be of good alternative against Culex quinquefasciatus compared to the synthetic pesticides (Anjali et al., 2012). The present study was carried out to evaluate the larvicidal activity of eucalyptus oil nanoemulsion against the mosquito larvae. The larvicidal studies were also carried out against $C x$. quinquefasciatus mosquito. Early third instars larvae of $C x$. quinquefasciatus mosquitoes were exposed for up to $24 \mathrm{~h}$ at various concentrations. Target the specific nature of nanoemulsion makes it an ideal larvicide against $C x$. quinquefasciatus. Moreover, it has proved to be ineffective against selected test microorganism, Rhizobium leguminosorum.

\section{Materials and methods}

\section{Materials}

Eucalyptus oil (Eucalyptus globulus) and nutrient agar was purchased from Himedia, India and stored at room temperature under laboratory conditions; Tween 80 (Polyoxyethylene 20 monooleate) was supplied from Sigma, India. Ultrapure water was obtained from Cascada ${ }^{\mathrm{TM}}$ Biowater System, Pall Corporation, USA, with a resistivity not less than, $18.2 \mathrm{M} \Omega \mathrm{cm}$, was used for the preparation of all solutions. All other chemicals used were of analytical reagent grade.

\section{Microorganism}

R. leguminosorum (MTCC 099) was obtained from National Chemical Laboratory (Pune, India). The strain was cultured in a $50 \mathrm{ml}$ nutrient broth at $37^{\circ} \mathrm{C}$ for $24 \mathrm{~h}$. Roughly $1 \mathrm{ml}$ of this grown culture was reinoculated again into a $50 \mathrm{ml}$ nutrient broth, and the growth was adjusted to $1 \times 10^{8}$ colony-forming units (CFU) $\mathrm{ml}^{-1}$ at $600 \mathrm{~nm}$ using phosphate-buffered saline (PBS).

\section{Methods}

\section{GC-MS analysis}

Eucalyptus oil composition was analyzed by GC-MS (GC model: Hp5890, series 2, MS model: 5971 A). Carrier gas used was helium gas at a flow rate of $3.0 \mathrm{ml} \mathrm{min}^{-1}$. The samples were injected with a split ratio of 1:100. Injector temperature was $80^{\circ} \mathrm{C}$ and detector temperature was $260^{\circ} \mathrm{C}$. Mass spectra was recorded over $60-260 \mathrm{amu}$ range with $70 \mathrm{eV}$ of ionization energy. The percentage composition was calculated using the peak normalization method assuming equal detector response. Identification of components of oil was done by matching the obtained mass spectra data with NIST library search.

\section{Preparation of nanoemulsion}

The oil-in-water nanoemulsion was formulated using eucalyptus oil, non-ionic surfactant (tween 80) and water. The concentration of eucalyptus oil $(6 \%, \mathrm{v} / \mathrm{v})$ was fixed for all the formulations. Initially, coarse emulsion was prepared by adding water to organic phase containing oil and surfactant in different ratios 1:1,1:2, and 1:3 (v/v) using a magnetic stirrer, which was then subjected to ultrasonic emulsification using a $20 \mathrm{kHz}$ Sonicator (Ultrasonics, USA) with a power output of $750 \mathrm{~W}$. Energy input was given through sonotrode containing a piezoelectric crystal with a probe diameter of $13 \mathrm{~mm}$. Sonicator probe generates disruptive forces that reduce the droplet diameter converting coarse emulsion to nanoemulsion. The characterization of nanoemulsions was carried out and the emulsion stability was investigated.

\section{Characterization of nanoemulsion}

Thermodynamic stability study. To prove the stability, formulated emulsion was subjected to different stress tests (Shafiq et al., 2007).

Centrifugation: The formulated nanoemulsions were centrifuged at $3000 \mathrm{rpm}$ for $30 \mathrm{~min}$ and observed for phase separation if any. Stable samples were further analyzed for heating, cooling, and freeze-thaw cycle.

Heating-cooling cycle: This was performed by keeping formulated nanoemulsion at 40 and $4^{\circ} \mathrm{C}$, alternating each temperature for $48 \mathrm{~h}$. The cycle was repeated thrice. This was done to check the stability of nanoemulsion at varying temperature.

Freeze-thaw stress: This was carried out by keeping the nanoemulsion alternatively at -21 and $25^{\circ} \mathrm{C}$ for $48 \mathrm{~h}$ at each temperature. The cycle was repeated twice. The experiment was performed in triplicates. The formulations that passed the thermodynamic stress tests were taken for further characterization studies.

Droplet size distribution and polydispersity index. The droplet size distribution (analysis by volume) and polydispersity index (PDI) of eucalyptus oil nanoemulsion formulation (1:2) was determined using a 90 plus particle size analyzer (Brookhaven Instruments Corporation, USA). The PDI is a measure of the homogeneity and stability of the droplet size in the nanoemulsion system. PDI values below 0.2 indicate a 
narrow size distribution and thus provide long-term stability to the formulated nanoemulsion. Prior to experiment, formulated emulsion was diluted with milli-Q (Millipore corporation) double-distilled water to trim down multiple scattering effects.

Morphology of emulsion droplets. To visualize the shape and morphology of the formulated nanoemulsions, transmission electron microscopy (TEM) was carried out. One drop of emulsion was negatively stained with phosphotungstic acid and was positioned on a copper grid. The TEM micrographs were acquired using a transmission electron microscope (Tecnai-10, Phillips) with a tungsten source and operating at $80 \mathrm{kV}$.

\section{Larvicidal bioassay}

Larvae. Mosquito larvae were collected from a waterstagnated area. Species identification was carried out in Zonal Entomological Research Laboratory, Vellore, Tamil Nadu, India. The mosquito larvae were identified as $C x$. quinquefasciatus. The collected larvae were acclimatized under proper temperature and humidity (Anjali et al., 2011).

Larvicidal activity. The larvicidal activity of eucalyptus oil nanoemulsion against Culex $\mathrm{sp}$. third instar larvae of $C x$. quinquefasciatus mosquitoes were treated with different percent concentrations of nano and bulk eucalyptus oil emulsions, following the standard WHO larval susceptibility test method (WHO, 2005). Twenty larvae of Culex sp. were placed in each of the five $250 \mathrm{ml}$ sterile beaker containing $200 \mathrm{ml}$ of water. After adding larvae to beakers containing 5, $50,100,150$, and 250 ppm of nanoemulsion (1:2), the bulk emulsion (1:2) was also added in each of the beakers, separately. A control was kept without addition of sample. The larvicidal effect of sample was monitored by recording mortality after $2,4,6,12$, and $24 \mathrm{~h}$ of the exposure period. The dead larvae were identified when they failed to move after probing with a needle in the siphon or cervical region. Each test was performed in six replicates. The percentages of larval mortality and standard deviation were calculated for each concentration of nanoemulsion and bulk emulsion.

Histological studies. For histological purposes, the treated and untreated third instar larvae of $C x$. quinquefasciatus were stored in $10 \%$ formalin solution. The material was then embedded and cut with glass knives in a rotary microtome. The sections were then stained with hematoxylin-eosin blue, which is used to study the morphological changes using phase contrast microscope (Carl Zeiss, USA) fitted with a digital camera and compared with the control sample (Al-Mehmadi \& Al-Khalaf, 2010).

Antibacterial susceptibility: well diffusion method. The susceptibility of bacteria to eucalyptus oil and nanoemulsion was determined by an agar well diffusion method (Lopez et al., 2005). The bacterial suspension $\left(100 \mu \mathrm{l}\right.$ of $\left.10^{7}-10^{8} \mathrm{CFU} \mathrm{ml}{ }^{-1}\right)$ was applied uniformly on the surface of a nutrient agar plate before making the wells on the plate. The plates were incubated at $37^{\circ} \mathrm{C}$ for $24 \mathrm{~h}$, after which, the average diameter of inhibition zone surrounding the well was measured with a ruler with up to $1 \mathrm{~mm}$ resolution. The experiments were performed in duplicates.

Preparation of whole body homogenates. The treated and control larvae were taken separately and washed with doubledistilled water and then dabbed with a tissue paper to remove the moisture until it was completely dry. About 20 larvae were homogenized along with $2 \mathrm{ml}$ of PBS in an Eppendorf tube. This homogenate was then subjected to centrifugation at $10,000 \mathrm{~g}$ for $20 \mathrm{~min}$, after which, the clear supernatant was retrieved and the pellet was discarded. The supernatant was placed on ice until further use for biochemical assays.

\section{Quantitative analysis of biochemical constituents \\ Determination of protein concentration}

The protein concentration of the control and treated larval homogenates was analyzed by Bradford method (1976).

\section{Acetylcholinesterase assays}

The activity of acetylcholinesterase in the larval homogenate was measured according to a method by Ikezawa \& Taguchi, (1981) with slight modification. $50 \mu \mathrm{l}$ of homogenate was successively mixed with $450 \mu \mathrm{l}$ of PBS (100 mM, pH 7.4), $50 \mu \mathrm{l}$ of $10 \mathrm{mM}$ 5-5-dithiobis 2-nitro benzoic acid and $50 \mu \mathrm{l}$ of $12.5 \mathrm{mM}$ acetylcholine iodide which acts as the substrate. The mixture was then incubated at room temperature for $5 \mathrm{~min}$ and at $400 \mathrm{~nm}$ the optical density was measured.

\section{Acid and alkaline phosphatase assay}

The acid and alkaline phosphatase activity of the larval homogenates was measured by a slightly modified version of the method by Asakura (1978). For the acid phosphatase assay, $100 \mu \mathrm{l}$ of the larval homogenate was taken with $400 \mu \mathrm{l}$ of $50 \mathrm{mM}$ sodium acetate buffer ( $\mathrm{pH} 4.0$ ) and $500 \mu \mathrm{l}$ of $15 \mathrm{mM}$ of p-nitrophenyl phosphate. For the alkaline phosphatise assay, $100 \mu \mathrm{l}$ of larval homogenate was taken along with $400 \mu \mathrm{l}$ of $50 \mathrm{mM}$ Tris- $\mathrm{HCl}$ buffer $(\mathrm{pH} 8.0)$ and $500 \mu \mathrm{l}$ of $15 \mathrm{mM}$ p-nitrophenyl phosphate. The individual mixtures were incubated for $5 \mathrm{~min}$ at $37^{\circ} \mathrm{C}$ in water bath. They were then treated with $100 \mu \mathrm{l}$ of $0.5 \mathrm{~N} \mathrm{NaOH}$ in order to stop the enzymatic reaction, the mixtures were then centrifuged at $4000 \mathrm{~g}$ for $5 \mathrm{~min}$. The optical density of the respective clear supernatants was measured at $440 \mathrm{~nm}$.

\section{Results \\ GC-MS analysis}

The chemical compound present in eucalyptus oil was identified by GC-MS analysis. Eucalyptol was found to be the major component of the oil with $17.73 \%$ of total peak area.

\section{Nanoemulsion formulation}

A volume of eucalyptus oil (6\%), Tween 80 and water was prepared using magnetic stirrer at $250 \mathrm{rpm}$ for $30 \mathrm{~min}$. The average diameter of 1:2 ratio of bulk emulsion was found to be $7224 \mathrm{~nm}$ and PDI is 0.890 . Also found to be unstable (phase separated) during thermodynamic stability study. This bulk emulsion was further subjected to 


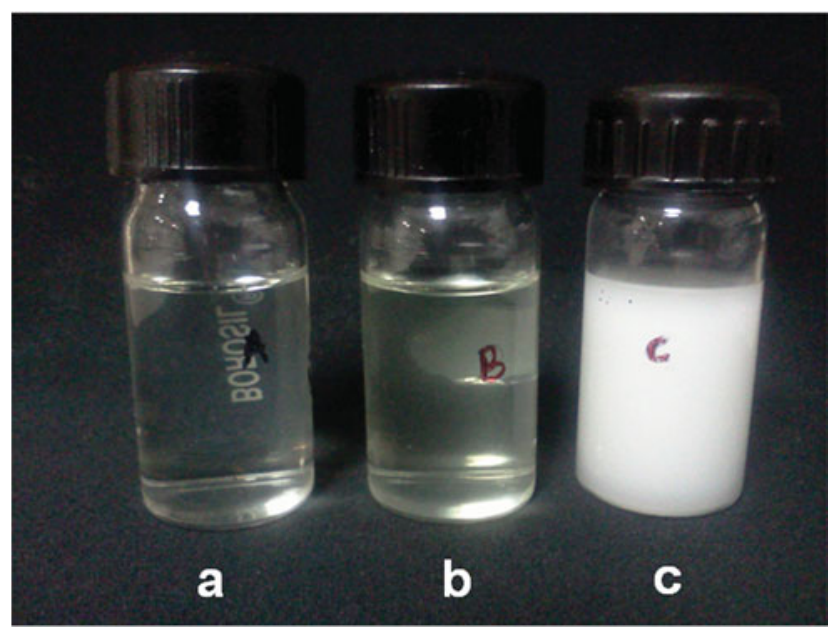

Fig. 1. Effect of sonication time on the visual appearance of eucalyptus oil nanoemulsions (a) 1:3; (b) 1:2; (c) 1:1.
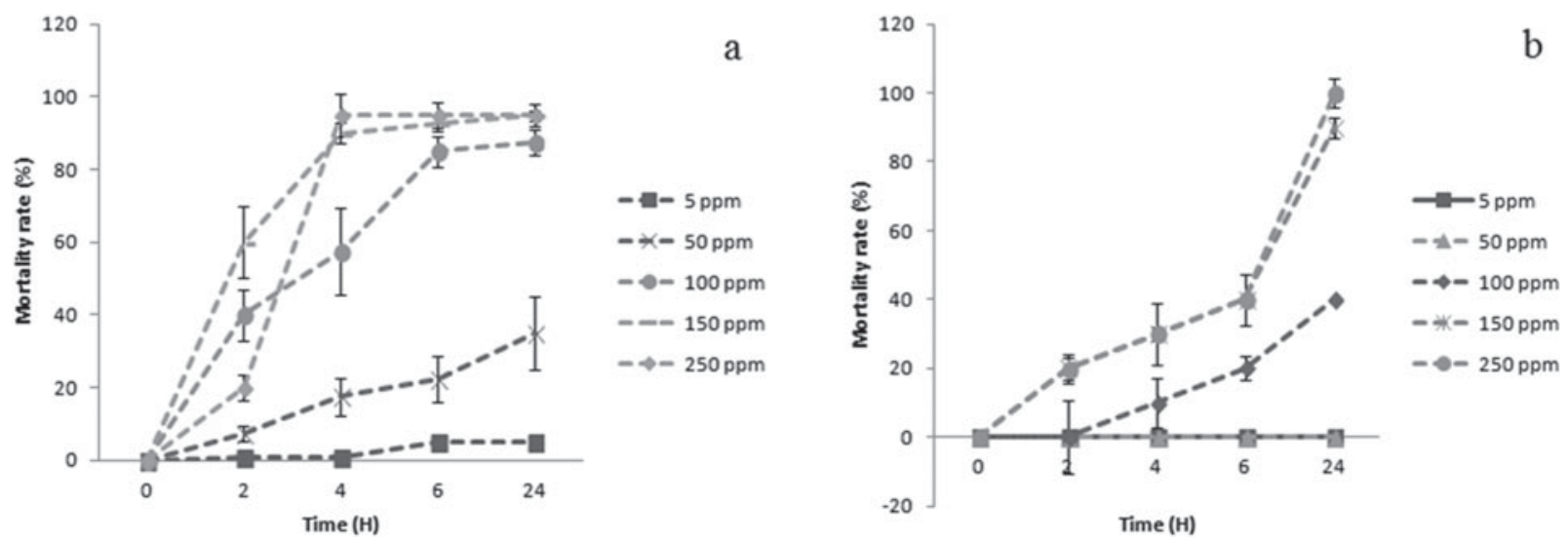

Fig. 2. A typical particle size distribution measurement by dynamic light scattering.

ultrasonication method and it has shown in fig. 1. It represents the visual appearance of nanoemulsion prepared by sonication with respect to three different ratios $(1: 3 ; 1: 2 ; 1: 1)$ as fig. 1a-c. The nanoemulsion of 1:2 ratios was found stable after thermodynamic stabilization cycle. The emulsion showed no phase separation. Even though, the nanoemulsion of the ratio 1:2 is stable; it is preferable to use fresh aliquots of the nanoemulsions.

\section{Characterization of the selected nanoemulsion}

Based on the thermodynamic stability study, 1:2 ratio nanoemulsions was selected and average diameter is $9.4 \mathrm{~nm}$ and their size distribution is shown in fig. 2. The polydispersity index (PI) of the nanoemulsions is 0.060 which shows that it is uniform. The particles are presented in TEM image. According to TEM evaluation, the particle size ranges from 20 to $40 \mathrm{~nm}$ and the droplets are spherical in nature (fig. 3). The nanoemulsion of the ratios $1: 1$ and 1:3 showed phase separation, thereby, rendering it for particle size analysis.

\section{Larvicidal activity of eucalyptus oil nanoemulsion against Cx. quinquefasciatus}

The larvicidal activity of eucalyptus oil nanoemulsion (1:2) and bulk emulsion (1:2) was recorded against $C x$. quinquefasciatus. The larvicidal activity of the nanoemulsion was compared with the bulk emulsion of the same. It was observed that at a concentration of $250 \mathrm{ppm}$ nanoemulsion, $98 \%$ mortality within $4 \mathrm{~h}$ of treatment was observed as shown in fig. $4 \mathrm{a}$, whereas, for the bulk emulsion, $100 \%$ mortality was observed at $24 \mathrm{~h}$ and is shown in fig. $4 \mathrm{~b}$. Thus, proves that the nanoemulsion formulation of eucalyptus oil is far more effective than bulk emulsion.

\section{Histopathology of larvae of Cx. quinquefasciatus}

The histological images (fig. 5) show that the midgut region of the Cx. quinquefasciatus larvae with and without treatment. Fig. 5a showed the control larvae in which the midgut region is intact, whereas, in fig. 5b, the image of the larvae after treatment shows that the peritrophic membrane (PM) and the 


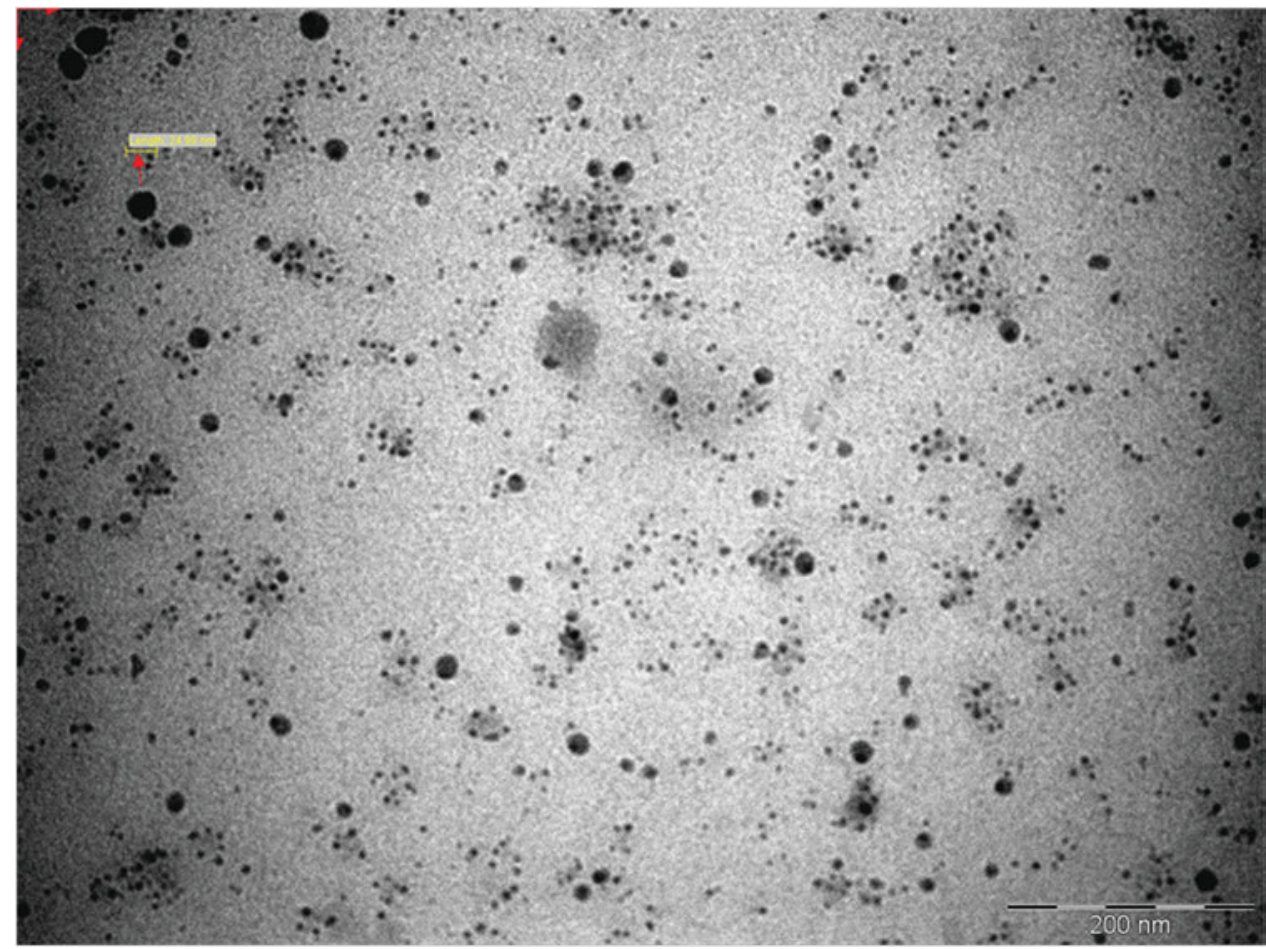

Fig. 3. TEM image of eucalyptus oil nanoemulsion.

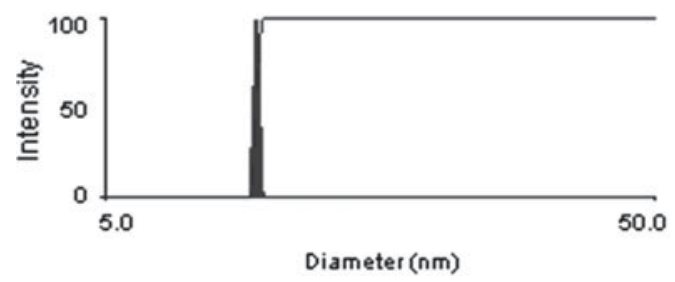

Fig. 4. (a) Mortality rate of eucalyptus oil nanoemulsions against $C x$. quinquefasciatus and (b) Mortality rate of eucalyptus oil bulk emulsion against $C x$. quinquefasciatus.

epithelial cells (EC) of the midgut have been damaged and there is also a leakage of the midgut contents.

\section{Antibacterial activity of nanoemulsion}

In order to evaluate the environmental impact of the nanoemulsion, its antimicrobial activity was evaluated for soil bacteria, R. leguminosorum. The tested strain exhibited no zone of inhibition (data not shown). It was observed that the bacterial strain was susceptible to eucalyptus oil and not for nanoemulsion formulations (1:3, 1:2, and 1:1) since; there was no formation of zones in the samples. Therefore, its nano form can be used as an environment friendly larvicidal agent.

\section{Quantification of biochemical constituents}

\section{Determination of protein concentration}

On exposure of the larvae to eucalyptus oil nanoemulsions, the total protein content has reduced from $0.1223 \mathrm{mg}$ protein $\mathrm{ml}^{-1}$ of homogenate of the controlled larvae to $0.1214 \mathrm{mg}$ protein $\mathrm{ml}^{-1}$ of the treated larval homogenate (fig. 6a). This result demonstrates that there is no significant level found in both control and treated larval homogenate of the total protein content.

\section{Acetylcholinesterase assay}

As depicted in fig. 6b, eucalyptus oil nanoemulsion affected esterase activities in the larvae of $C x$. quinquefasciatus. The level of acetylcholinesterase activity in the control larvae was $0.231 \mathrm{lM}$ acetylcholinesterase released $\mathrm{min}^{-1} \mathrm{mg}^{-1}$ protein, and it gradually decreased to $0.05 \mathrm{lM}$ acetylcholinesterase released $\mathrm{min}^{-1} \mathrm{mg}^{-1}$ protein in the larvae exposed to nanoemulsion for $24 \mathrm{~h}$. The optical density of the larval homogenate of the larvae-treated nanoemulsion showed a reduction of 0.184 when compared with control larvae.

\section{Acid and alkaline phosphatase assay}

Exposure to eucalyptus oil nanoemulsion, there was a decrease of 0.13 in the absorbance of the larval homogenate when compared to homogenate of the control larvae, thus, showing a reduction in the acid phosphatase enzyme. In fig. $6 c, d$, there was a reduction in the levels of alkaline phosphatase enzyme. Also, the difference in absorbance between the control and treated larvae was found to be 0.11 . The level of acid phosphatase activity significantly decreased from the control value of 0.45 to $0.322 \mathrm{mM}$ p-nitrophenol released $\mathrm{min}^{-1} \mathrm{mg}^{-1}$ protein upon exposure of the larvae to nanoemulsion for $24 \mathrm{~h}$. Also, the level of alkaline phosphatase decreased from 0.09 to $0.05 \mathrm{mM}$ p-nitrophenol released 

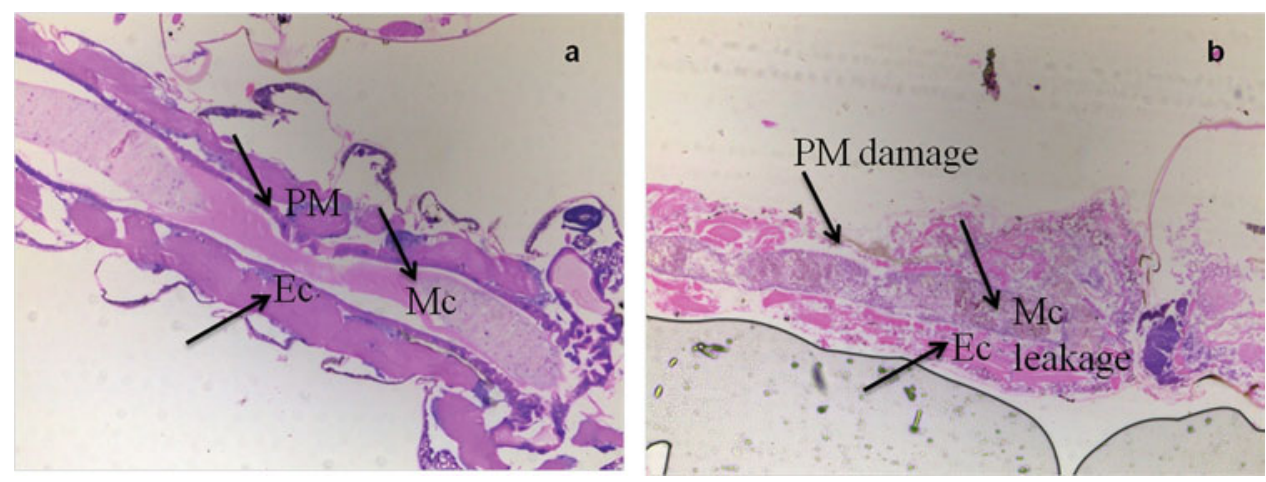

Fig. 5. (a) Midgut of Cx. quinquefasciatus larvae; EC - epithelial cells, PM - peritrophic membrane, MC - midgut contents and (b) Midgut of the larvae that have been treated with eucalyptus oil nanoemulsions. The image shows damage to EC and PM and leakage of MC.
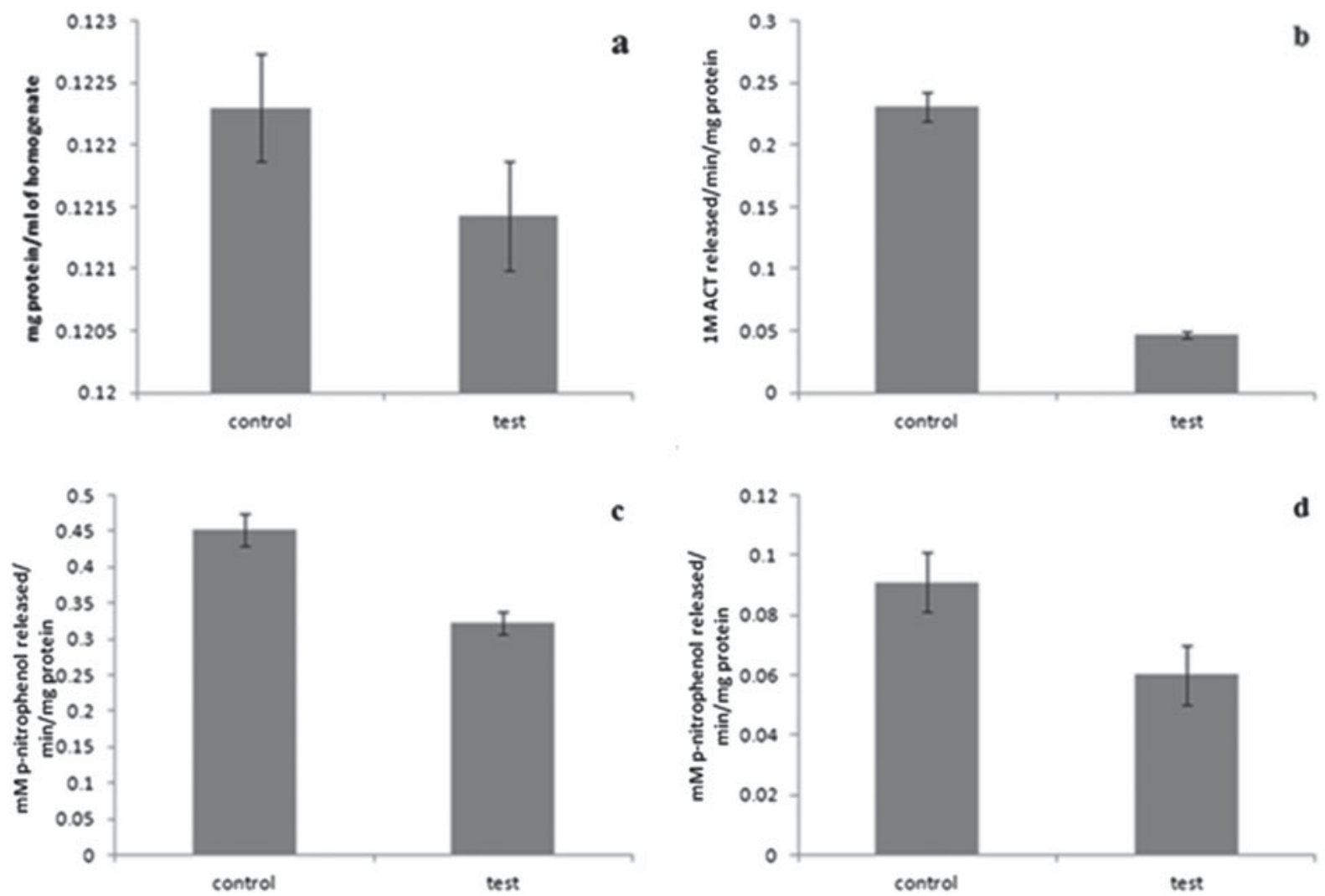

Fig. 6. Biochemical assays of control and treated larval homogenates. (a) Protein assay. (b) Acetylcholinesterase assay. (c) Acid assay. (d) Alkaline phosphatase assay.

$\min ^{-1} \mathrm{mg}^{-1}$ protein in the third instar larvae of $C x$. quinquefasciatus exposed to nanoemulsion.

\section{Discussion}

Cx. quinquefasciatus serves as the vector for the nematode Wuchereria bancrofti that causes filariasis. The ideal method of controlling mosquitoes is by targeting them at the stage at which they are vulnerable i.e., the larval stage. Therefore, mosquitoes can be controlled by application of insecticides to their habitat, where, the mobility of the larvae is low (Wiseman \& Chapagain, 2005).

The use of synthetic-based pesticides over the past few years has increased the resistance toward the vectors (Wirth \& Georghiou, 1999; Rodriguez et al., 2002; Macoris et al., 2003), thus, instilling the need for finding alternative ways to control mosquitoes. The plant-based pesticides are in high demand, because, they are sustainable in the environment; they are safe and are also pleasant to use (Maia \& Moore, 2011). The plantbased compounds have natural pesticide activity, because, 
they contain certain bioactive compounds that prevent them from being eaten by herbivores. Although, the main function of these compounds is defense against plant-eating insects, the volatile compounds released as a result of herbivores have mosquito repellent properties (Pichersky \& Gershenzon, 2002).

Eucalyptus oil is the oil distilled from the leaves of eucalyptus, a genus of the plant family Myrtaceae. In the study carried out by Mandal (2011), the repellent activity of eucalyptus oil was demonstrated against $C x$. quinquefasciatus. Eucalyptus oil is among the essential oils that have been registered as an insect repellent by US Environmental Protection Agency (US EPA) (Katz et al., 2008). The seed and leaf extract of eucalyptus oil contain compounds that are toxic to mosquito larvae (Elbanna, 2006) that are in agreement with the study carried out by Brooker \& Kleinig (1990).

The steam distillation of aromatic plants and their derivatives yield essential oils that are rich in bioactive compounds, which forms non-toxic compounds when they undergo degradation. Since, they do not cause any adverse health effects; they are used as insect repellents and a safe and eco-friendly alternative to synthetic pesticides (Isman, 2000). In the past, essential oils have been shown to have good activity against mosquitoes (Gillij et al., 2008). It was observed that essential oils of many plants exhibited mosquito larvicidal activity (Phasomkusolsil \& Soonwera, 2010).

A problem that arises with the use of essential oils as pesticides is that their effect is short lasting (Barnard \& Xue, 2004). To overcome this problem, essential oils are formulated into nanoemulsions. It also has technological limitations, such as hydrophobicity, reactivity, and volatility of the bioactive molecules constituting the essential oils (Huang et al., 2010). This problem may be overcome by formulating Essential oils (EOs) into nanoemulsion which is transparent and can be used in food and beverage products, thereby, decreasing the amount of EOs required (Qian et al., 2012). The emulsions that have droplets which are very small with size ranging from 20 to $200 \mathrm{~nm}$ are called nanoemulsions. The method of preparation determines the stability of the formulated nanoemulsion.

The nanoemulsions are formed when the oil phase is dispersed in an aqueous phase and it is stabilized due to the presence of surfactant that forms a layer at the interface of the droplet, thus, separating the oil from aqueous phase owing to the stability of emulsion (Tadros et al., 2004; McClements et al., 2007; Acosta, 2009). The attractive forces between the droplets is proportional to the size of the droplets and so when the size of the droplets are in the nano range, the attractive forces between the droplets are weak, thereby, preventing particle aggregation and helps in making the nanoemulsions more stable (Tadros et al., 2004; McClements, 2005). The stabilization of the nanoemulsions is also dependent on the steric effect of the non-ionic surfactant (Tadros et al., 2004).

The eucalyptus oil nanoemulsion was prepared in three ratios by varying the volumes of oil, surfactant, and water. The ratios were 1:1, 1:2, and 1:3, respectively. The uniformity and stability of the nanoemulsion can be determined by the PI. The PI is inversely proportional to the uniformity and stability of the nanoemulsion. The lower the PI, more stable the nanoemulsion (Shinoda \& Saito, 1969).

In this study, eucalyptus oil $(6 \%, v / v)$ is mixed with a non-ionic surfactant, tween 80 along with water, which is used as an aqueous phase. This emulsion is then subjected to ultrasonication that breaks down the bulk emulsion into an emulsion comprising droplets having the size in nanometer range. This increases the surface area of the droplets, thereby, increasing the reactivity; thus, making nanoemulsions more effective than its bulk counterpart. The larvicidal activity of the nanoemulsion is expected due to the presence of eucalyptol, which is the major component of the eucalyptus oil by GC-MS analysis.

A number of compounds present in relatively high concentrations in the essential oil of E. globulus used in the present study are known to have larvicidal properties. In particular, it is worth to note 1,8-cineole (eucalyptol), which accounted for approximately $17.73 \%$ of the total essential oil of E. globulus. Several researchers have reported that the insecticidal and antimicrobial activity of an essential oil is linked to its chemical composition (Inouye et al., 2001; Cimanga et al., 2002; Kumar et al., 2011).

This is the first time that a nanoemulsion formulation using eucalyptus oil with a small droplet size (Z-average diameter) of $9.3 \mathrm{~nm}$ has been reported against $C x$. quinquefasciatus. The size-based effect was demonstrated in a study conducted by Anjali et al. (2011), where, nanopermethrin was found to be more effective against larvae of $C x$. quinquefasciatus when compared to bulk permethrin. From the same group Anjali et al. (2012), the neem oil nanoemulsion showed higher mortality rate against $C x$. quinquefasciatus larvae which is based on droplet size distribution. Similarly nanoemulsion formulation with use of essential oils was studied for various applications include drug delivery, cosmetics, antimicrobials, and nutraceuticals (Tadros et al., 2004; Shafiq et al., 2007; Rao \& McClements, 2011; Ziani et al., 2011).

The larvicidal activity of the eucalyptus oil nanoemulsion was compared with the bulk emulsion of the same. The nanoemulsion of the eucalyptus oil was found to be more effective than its bulk counterpart. The observed histopathological effects of the eucalyptus oil nanoemulsion on Cx. quinquefasciatus was in agreement with the results obtained by Suresh Kumar et al. (2013), where, it is stated that the midgut of the Aedes aegypti treated with nanopermethrin showed damage of the PM and EC and leakage of the midgut content.

According to earlier studies, it is shown that the protein concentration of larvae decreases on treatment with biocides that is in agreement with the results of our present study. The larvae and pupae of A. aegypti showed a decrease in the protein concentration levels on exposure to extracts of the kernel of soapnut, Sapindus emarginatus according to a study conducted by Koodalingam et al. (2011). The nymphs of the coleopteran, Callosobruchus maculatus, showed a decrease in the levels of protein concentration on exposure to an insecticidal leaf lectin from Bauhinia monandra according to a study conducted by Macedo et al. (1997). According to a recent study conducted by Koodalingam et al. (2012), there was a noticeable decrease in protein concentration levels of the larvae of $A$. aegypti on exposure to a Bt-based product.

Esterases are the main enzymes that are responsible for resistance mechanism against chemical insecticides in mosquitoes (Brogdan \& McAllister, 1998). There was a significant decrease in the levels of acetylcholinesterase in the larvae of A. aegypti that were treated with extract of the kernel of soapnut (Koodalingam et al., 2011). In a study conducted by Koodalingam et al. (2012), there was a significant decrease in the levels of acetylcholinesterase in A. aegypti larvae that were treated with the Bt-based product, Vectobar. These findings are in accordance with the results of the present study, 
where, there is a significant decrease in the levels of acetylcholinesterase activity in the larvae that are treated with the eucalyptus oil nanoemulsion as compared with the untreated larvae.

The hydrolytic cleavage of phosphoric acid esters are catalyzed by acid and alkaline phosphatase enzymes and they play a significant role in metabolism and cell signalling processes (Walter \& Schutt, 1974; Torres \& Forman, 2006).

The larvae of Cnaphalocrocis medinalis when exposed to plant secondary metabolites showed a decrease in the levels of acid and alkaline phosphatase enzymes (Nathan et al., 2007). These findings are in accordance with the result of the present studies, in which, there is a decrease in the levels of acid and alkaline phosphatase enzymes in the larvae that were treated with eucalyptus oil nanoemulsions.

\section{Conclusion}

Eucalyptus oil being a plant-based component is ecofriendly and has natural pesticide activity. The nanoemulsion formulation of eucalyptus oil ensures higher efficacy as a larvicidal agent against $C x$. quinquefasciatus when compared to its bulk counterpart. From this study, it can be concluded that eucalyptus oil nanoemulsion can be used as a safe and effective alternative in the control of vector-borne diseases caused by mosquito larvae.

\section{Acknowledgements}

The authors acknowledge VIT University for the research fund extended by them for the completion of this work. Authors also thank Mr Gopalrathinam, Senior Entomologist, Zonal Entomological Research Laboratory, Vellore, Tamil Nadu, for identifying Cx. quinquefasciatus mosquito larvae and Mr Suresh Kumar R.S. is greatly acknowledged for histopathology studies of $C x$. quinquefasciatus larvae.

\section{References}

Acosta, E. (2009) Bioavailability of nanoparticles in nutrient and nutraceutical delivery. Current Opinion in Colloid and Interface Science 14, 3-15.

Al-Mehmadi, R.M. \& Al-Khalaf, A.A. (2010) Larvicidal and histological effects of Melia azedarach extract on Culex quinquefasciatus Say larvae (Diptera: Culicidae). Journal of King Saud University 22, 77-85.

Anjali, C.H., Sudheer Khan, S., Goshen, K.M., Magdassi, S., Mukherjee, A. \& Chandrasekaran, N. (2011) Formulation of water dispersible nanopermethrin for larvicidal applications. Ecotoxicology and Environmental Safety 73, 1932-1936.

Anjali, C.H., Sharma, Y., Mukherjee, A. \& Chandrasekaran, N. (2012) Neem oil (Azadirachta indica) nanoemulsion - a potent larvicidal agent against Culex quinquefasciatus. Pest Management Science 68, 158-163.

Anton, N., Gayet, P., Benoit, J.P. \& Saulnier, P. (2007) Nanoemulsions and nanocapsules by the PIT method: an investigation on the role of the temperature cycling on the emulsion phase inversion. International Journal of Pharmaceutics 344, 44-52.

Asakura, K. (1978) Phosphatase activity in the larvae of the euryhaline mosquito, Aedes togoi Theobold, with special reference to sea water adaptation. Journal of Experimental Marine Biology and Ecology 31, 325-337.
Barnard, D.R. \& Xue, R.D. (2004) Laboratory evaluation of mosquito repellents against Aedes albopictus, Culex nigripalpus, and Ochlerotatus triseriatus (Diptera: Culicidae). Journal of Medical Entomology 41, 726.

Batish, D.R., Singh, H.P., Kohli, R.K. \& Kaur, S. (2008) Eucalyptus essential oil as a natural pesticide. Forest Ecology and Management 256, 2166-2174.

Becker, N., Petriae, D., Zgomba, M., Boase, C., Dahl, C., Lane, J. \& Kaiser, A. (2003) Mosquitoes and Their Control. New York, Kluwer Academic Plenum Publisher, pp. 1-16.

Bouchemal, K., Briancon, S., Perrier, E. \& Fessi, H. (2004) Nanoemulsion formulation using spontaneous emulsification: solvent, oil and surfactant optimisation. International Journal of Pharmaceutics 280, 241-251.

Bradford, M.M. (1976) A rapid and sensitive method for quantitation of microgram quantities of protein utilizing the principle of protein dye binding. Analytical Biochemistry 72, 248-254.

Brogdan, W.G. \& McAllister, J.C. (1998) Insecticide resistance and vector control. Emerging Infectious Diseases Journal 4, 605-613.

Brooker, M. \& Kleinig, D. (1990) Field Guide to the Eucalyptus, Vol. 1. Revised edn. Melbourne and Sydney, South-Eastern Australia, Inkata Press.

Cimanga, K., Kambu, K., Tona, L., Apers, S., De Bruyne, T., Hermans, N., Totte, J., Pieters, L. \& Vlietinck, A.J. (2002) Correlation between chemical composition and antibacterial activity of essential oils of some aromatic medicinal plants growing in the Democratic Republic of Congo. Journal of Ethnopharmacology 79, 213-220.

Elbanna, S.M. (2006) Larvaecidal effects of eucalyptus extract on the larvae of Culex pipiens mosquito. International Journal of Agriculture and Biology 8, 896-897.

Gillij, Y.G., Gleiser, R.M. \& Zygadlo, J.A. (2008) Mosquito repellent activity of essential oils of aromatic plants growing in Argentina. Bioresource Technology 99, 25072515.

Global Health (2010). Division of parasitic Diseases and Malaria. "About Malaria: Malaria" 8 February 2010. CDC, Global Health - Division of Parasitic Diseases. 08 May 2010. http: / / www.cdc.gov/malaria/about/index.html

Huang, Q.R., Yu, H.L. \& Ru, Q.M. (2010) Bioavailability and delivery of nutraceuticals using nanotechnology. Journal of Food Science 75, R50-R57.

Ikezawa, H. \& Taguchi, R. (1981) Phosphatidylinositol-specific phospholipase C from Bacillus cereus and Bacillus thuringiensis. Methods in Enzymology 71, 731-741.

Inouye, S., Yamaguchi, H. \& Takizawa, T. (2001) Screening of the antibacterial effects of variety of essential oils on respiratory tract pathogens, using a modified dilution assay method. Journal of Infection Chemotherapy 7, 251-254.

Isman, M.B. (2000) Plant essential oils for pest and disease management. Crop Protection 19, 603-608.

Katz, T., Miller, J. \& Hebert, A. (2008) Insect repellents: historical perspectives and new developments. Journal of the American Academy of Dermatology 58, 865-871.

Klang, V., Nadejda, B.M., Valenta, C. \& Hofer, F. (2012) Electron microscopy of nanoemulsions: an essential tool for characterisation and stability assessment. Micron 43, 85-103.

Koodalingam, A., Mullainadhan, P. \& Arumugam, M. (2011) Effects of extract of soap nut Sapindus emarginatus on esterases and phosphatases of the vector mosquito, Aedes aegypti (Diptera: Culiciae). Acta Tropica 118, 27-36. 
Koodalingam, A., Mullainadhan, P., Rajalakshmi, A.M., Deepalakshmi, R. \& Ammu, M. (2012) Effect of a Bt-based product (Vectobar on esterases and phosphatases from larvae of the mosquito Aedes aegypti. Pesticide Biochemistry and Physiology 104, 267-272.

Kumar, P., Mishra, S., Malik, A. \& Satya, S. (2011) Repellent, larvicidal and pupicidal properties of essential oils and their formulations against the housefly, Musca domestica. Medical and Veterinary Entomology 25, 302-310.

Kumar, P., Mishra, S., Malik, A. \& Satya, S. (2012) Compositional analysis and insecticidal activity of Eucalyptus globules (family: Myrtaceae) essential oil against housefly (Musca domestica). Acta Tropica 122, 212-218.

Lopez, P., Sanchez, C., Batlle, R. \& Nerin, C. (2005) Solid- and vapor-phase antimicrobial activities of six essential oils: susceptibility of selected foodborne bacterial and fungal strains. Journal of Agricultural and Food Chemistry 53, 69396946.

Macedo, M.L.R., Freire, M.G.M., Silva, M.B.R. \& Coelho, L.C.B.B. (1997) Insecticidal action Bauhinia monandra leaf lectin (BmoLL) against Anagasta kuehniella (Lepidoptera: Pyralidae), Zabrotes subfasciatus and Callosobruchus maculates (Coleoptera: Bruchidae). Comparative Biochemistry and Physiology - Part A: Molecular and Integrative Physiology 146, 486-498.

Macoris, M.D., Andrighetti, M.T.M., Takaku, L., Glasser, C.M., Garbeloto, V.C. \& Bracco, J.E. (2003) Resistance of Aedes aegypti from the State of Sao Paulo, Brazil, to organophosphates insecticides. Memorias do Instituto Oswaldo Cruz 98, 703-708.

Maia, M.F. \& Moore, S.J. (2011) Plant-based insect repellents: a review of their efficacy, development and testing. Malaria Journal 10(1), S11.

Mandal, S. (2011) Repellent activity of Eucalyptus and Azadirachta indica seed oil against the filarial mosquito Culex quinquefasciatus Say (Diptera: Culicidae) in India. Asian Pacific Journal of Tropical Biomedicine S109-S112.

McClements, D.J. (2005) Food Emulsions: Principles, Practice, and Techniques. 2nd edn. Boca Raton, CRC.

McClements, D.J., Decker, E.A. \& Weiss, J. (2007) Emulsion based delivery systems for lipophilic bioactive components. Journal of Food Science 72, 109-124.

Nathan, S.S., Choi, M.Y., Paik, C.H. \& Seo, H.Y. (2007) Food consumption, utilization and detoxification enzyme activity of the rice leaf folder larvae after treatment with Dysoxylum triterpenes. Pesticide Biochemistry and Physiology 88, 260-267.

Papachristos, D.P. \& Stamopoulos, D.C. (2004) Fumigant toxicity of three essential oils on the eggs of Acanthoscelides obtectus (Say) (Coleoptera: Bruchidae). Journal of Stored Products Research 40, 517-525.

Phasomkusolsil, S. \& Soonwera, M. (2010) Potential larvicidal and pupacidal activities of herbal essential oils against Culex quinquefasciatus Say and Anopheles minimus (Theobald). The Southeast Asian Journal of Tropical Medicine and Public Health 41, 1342-1351.

Pichersky, E. \& Gershenzon, J. (2002) The formation and function of plant volatiles: perfumes for pollinator attraction and defense. Current Opinion in Plant Biology 5, 237-243.

Qian, C., Decker, E.A., Xiao \& McClements, D.J. (2012) Physical and chemical stability of $\beta$-carotene-enriched nanoemulsions: Influence of $\mathrm{pH}$, ionic strength, temperature, and emulsifier type. Food Chemistry 132, 1221-1229.

Rao, J. \& McClements, D.J. (2011) Formation of flavor oil microemulsions, nanoemulsions and emulsions: influence of composition and preparation method. Journal of Agricultural and Food Chemistry 59, 5026-5035.

Rodriguez, M.M., Bisset, J., Ruiz, M. \& Soca, A. (2002) Crossresistance to pyrethroid and organophosphorus insecticides induced by selection with temephos in Aedes aegypti (Diptera: Culicidae) from Cuba. Journal of Medical Entomology 39, 882888.

Shafiq, S., Shakeel, F., Talegoankar, S., Ahmad, F.J., Khar, R.K. \& Ali, M. (2007) Development and bioavailabiltiy assessment of ramipril nanoemulsion formulation. European Journal of Pharmaceutics and Biopharmaceutics 66, 227-243.

Shinoda, K. \& Saito, H. (1969) The stability of O/W type emulsions as functions of temperature and the HLB of emulsifiers: the emulsification by PIT-method. Journal of Colloid and Interface Science 30, 258-263.

Silva, W.J., Doria, G.A.A., Maia, R.T., Nunes, R.S., Carvalho, G.A., Blank, A.F., Alves, P.B., Marcal, R.M. \& Cavalcanti, S.C.H. (2008) Effects of essential oils on Aedes aegypti larvae: alternatives to environmentally safe insecticides. Bioresource Technology 99, 3251-3255.

Sole, I., Pey, C.M., Maestro, A., Gonzalez, C., Porras, M., Solans, C. \& Gutierrez, J.M. (2010) Nano-emulsions prepared by the phase inversion composition method: preparation variables and scale up. Journal of Colloid and Interface Science 344, 417-423.

Sukumar, K., Perich, M.J. \& Boobar, L.R. (1991) Botanical derivatives in mosquito-control - a review. Journal of the American Mosquito Control Association 7, 210-237.

Suresh Kumar, R.S., Shiny, P.J., Anjali, C.H., Jerobin, J., Goshen, K.M., Magdassi, S., Mukherjee, A. \& Chandrasekaran, N. (2013) Distinctive effects of nano-sized permethrin in the environment. Environmental Science and Pollution Research 20, 2593-2602.

Tadros, T., Izquierdo, P., Esquena, J. \& Solans, C. (2004) Formation and stability of nanoemulsions. Advances in Colloid and Interface Science 108-109, 303-318.

Takegami, S., Kitamura, K., Kawada, H., Matsumoto, Y., Kitade, T., Ishida, H. \& Nagata, C. (2008) Preparation and characterization of a new lipid nano-emulsion containing two cosurfactants, sodium palmitate for droplet size reduction and sucrose palmitate for stability enhancement. Chemical and Pharmaceutical Bulletin 56, 1097-1102.

Tennyson, S., Ravindran, K.J. \& Arivoli, S. (2012) Screening of twenty five plant extracts for larvicidal activity against Culex quinquefasciatus Say (Diptera: Culicidae). Asian Pacific Journal of Tropical Biomedicine S1130-S1134.

Torres, M. \& Forman, H.J. (2006) Signal transduction. Encyclopedia of Respiratory Medicine, pp. 10-18.

Trigg, J.K. (1996) Evaluation of eucalyptus-based repellent against Anopheles spp. in Tanzania. Journal of the American Mosquito Control Association 12, 243-246.

Walter, K. \& Schutt, C. (1974) Phosphatases. pp. 856-870 in Bergmeyer, H.U. (Ed.) Methods of Enzymatic Analysis. New York, Academic Press.

Wang, L., Li, X., Zhang, G., Dong, J. \& Eastoe, J. (2007) Oil-inwater nanoemulsions for pesticide formulations. Journal of Colloid and Interface Science 314, 230-235.

WHO (2005) Guidelines for laboratory and field testing of mosquito larvicides, CDS/WHOPES/GCDPP/05.13.

Wirth, M.C. \& Georghiou, G.P. (1999) Selection and characterization of temephos resistance in a population of Aedes aegypti from Tortola, British Virgin Islands. Journal of the American Mosquito Control Association 15, 315-320. 
Wiseman, Z. \& Chapagain, B.P. (2005) Larvicidal effects of aqueous extracts of Balanites aegyptiaca (desert date) against the larvae of Culex pipiens mosquitoes. African Journal of Biotechnology 4(11), 1351-1354.

Yilmaz, E. \& Borchert, H.H. (2005) Design of a phytosphingosinecontaining, positively charged nanoemulsion as a colloidal carrier system for dermal application of ceramides. European Journal of Pharmaceutics and Biopharmaceutics 60, 91-98.

Ziani, K., Chang, Y., McLandsborough, L. \& McClements, D.J. (2011) Influence of surfactant charge on antimicrobial efficacy of surfactant-stabilized thyme oil nanoemulsions. Journal of Agricultural and Food Chemistry 59(11), 6247-55. 